Illinois State University

ISU ReD: Research and eData

Theses and Dissertations

3-19-2017

\title{
Alterations in Foot Positioning During Ankle Taping and its Effects on Range of Motion and Jump Performance in Dancers
}

\author{
Eilish Anderson \\ Illinois State University, eilish.anderson14@gmail.com
}

Follow this and additional works at: https://ir.library.illinoisstate.edu/etd

Part of the Kinesiology Commons

\section{Recommended Citation}

Anderson, Eilish, "Alterations in Foot Positioning During Ankle Taping and its Effects on Range of Motion and Jump Performance in Dancers" (2017). Theses and Dissertations. 650.

https://ir.library.illinoisstate.edu/etd/650

This Thesis is brought to you for free and open access by ISU ReD: Research and eData. It has been accepted for inclusion in Theses and Dissertations by an authorized administrator of ISU ReD: Research and eData. For more information, please contact ISUReD@ilstu.edu. 


\title{
ALTERATIONS IN FOOT POSITIONING DURING ANKLE TAPING AND ITS EFFECTS ON RANGE OF MOTION AND JUMP PERFORMANCE IN DANCERS
}

\author{
Eilish Anderson
}

\section{Pages}

Context: A closed basket-weave ankle tape application is commonly used by healthcare professionals to provide support to the athlete's ankle during activity. This closed basket-weave ankle tape is used to prevent the ankle joint from going into excessive plantarflexion and inversion. Previous research has demonstrated traditional ankle taping techniques, with the ankle in a dorsiflexed position, reduces range of motion at the ankle. Dance requires athletes to place their ankle in a maximally plantarflexed position. It is unclear if traditional taping techniques applied in a dorsiflexed position allow dancers to achieve this range of motion. Further, no previous studies have examined taping an ankle in a neutral or slightly plantarflexed position. Objective: The purpose of this study is to identify whether taping an ankle in a neutral position, rather than a dorsiflexed position, will provide the similar range of motion restraints, while not hindering jump performance. Design: This was an assessor-blinded, crossover study to assess the difference in taping position and its effect on ankle range of motion, and ground reaction force at the ankle. Participants: Participants were recruited from the Dance Performance undergraduate program at the host institution. Inclusion criteria included dancers with no history of ankle injury within the past 6 months, no history of surgery on the ankle joint in the past 12 months. Participants also needed to have five or more years of experience in either ballet, modern, or jazz. Interventions: The independent variable was the position of the ankle during the ankle 
taping. Main Outcome Measures: The dependent variables assessed were range of motion measurements immediately after tape application and peak ground reaction force during a bipedal vertical jump while taped in each condition. Results: There was statistical significance in range of motion between no-tape and the taped conditions. No significant difference was found in range of motion between the two tape conditions. No significant difference in ground reaction force between all conditions. Conclusions: The positioning of the foot, whether it be dorsiflexed or neutral, does not affect jump performance and restricts range of motion similarly when applying a closed basket-weave ankle tape. Word Count: 353

KEYWORDS: Ankle, Ankle Tape, Jump Performance, Dancers 


\title{
ALTERATIONS IN FOOT POSITIONING DURING ANKLE TAPING AND ITS EFFECTS ON RANGE OF MOTION AND JUMP PERFORMANCE IN DANCERS
}

\author{
EILISH ANDERSON
}

A Thesis Submitted in Partial Fulfillment of the Requirements for the Degree of

\section{MASTER OF SCIENCE}

School of Kinesiology and Recreation

\section{ILLINOIS STATE UNIVERSITY}


Copyright 2017 Eilish Anderson 


\title{
ALTERATIONS IN FOOT POSITIONING DURING ANKLE TAPING AND ITS EFFECTS ON RANGE OF MOTION AND JUMP PERFORMANCE IN DANCERS
}

\author{
EILISH ANDERSON
}

COMMITTEE MEMBERS:

Justin Stanek, Co-Chair

Todd McLoda, Co-Chair 


\section{ACKNOWLEDGMENTS}

I would first like to thank Dr. Stanek and Dr. McLoda for their help and guidance in this thesis research project. Dr. Michael Torry and Dr. Adam Jagodinsky for their biomechanical guidance. Sara Semonis and the Undergraduate Dance Program for their participation. Jessica Pletsch and Luke Heilman for their assistance with data collection. Kelly Jo Trimble, Meg Schneider, and Amanda Donahue for their athletic training expertise with dancers. My dance teachers and athletic training mentors for their inspiration. My friends and family for their love and support.

E.A. 


\section{CONTENTS}

Page

ACKNOWLEDGMENTS

$\begin{array}{ll}\text { CONTENTS } & \text { ii }\end{array}$

TABLES

FIGURES

CHAPTER I: INTRODUCTION 1

CHAPTER II: REVIEW OF LITERATURE

Ankle Anatomy $\quad 3$

Ankle Injury $\quad 6$

$\begin{array}{ll}\text { Ankle Taping } & 7\end{array}$

Dance Biomechanics $\quad 11$

$\begin{array}{ll}\text { Conclusion } & 14\end{array}$

$\begin{array}{ll}\text { CHAPTER III: METHODS } & 15\end{array}$

$\begin{array}{ll}\text { Study Design } & 15\end{array}$

$\begin{array}{ll}\text { Participants } & 15\end{array}$

$\begin{array}{ll}\text { Instrumentation } & 16\end{array}$

$\begin{array}{ll}\text { Procedure } & 16\end{array}$

$\begin{array}{ll}\text { Ankle Tape Procedure } & 17\end{array}$

$\begin{array}{ll}\text { Ankle Range of Motion Measurement } & 18\end{array}$

Ground Reaction Force Measurement 19

$\begin{array}{ll}\text { Data Reduction and Statistical Analysis } & 20\end{array}$ 
CHAPTER IV: RESULTS

CHAPTER V: DISSCUSSION

Limitations

Future Research

Conclusion

26

REFERENCES

27 


\section{TABLES}

Table

Page

1. Means and Standard Deviations 


\section{FIGURES}

Figure $\quad$ Page

1 a-c. Sauté Jump 13

2a. Neutral Foot 17

2b. Dorsiflexed Foot 17

3. Vicon System Data 19 


\section{CHAPTER I}

\section{INTRODUCTION}

Injuries to the ankle are among the most commonly treated ailment by healthcare professionals. On average about $20 \%$ of injuries are related to the ankle joint. ${ }^{1}$ Of those ankle injuries, $33-73 \%$ of them are diagnosed as an ankle sprains. ${ }^{1}$ Many ankle sprains are on the lateral side of the joint due to an inversion mechanism of the ankle joint. ${ }^{1}$

A closed basket-weave ankle tape technique is commonly used by healthcare professionals to provide support to an athlete's ankle joint during activity as a prophylactic device or to offer further support after sustaining an ankle injury. This closed basket-weave ankle tape is used to partially restrict the movement of the ankle joint in a plantar flexed, inverted position that was the likely mechanism for the initial injury. ${ }^{2,3}$ Literature has acknowledged ankle taping can limit range of motion of the ankle, and maintain athletic performance. ${ }^{4-32}$

Studies have examined ankle tape application and its effects on range of motion before and after activity. $4,7-10,14,17-21,23-25,28,33,34$ While applying this tape, the athlete's ankle is usually in a dorsiflexed position. Karlsson et al $^{14}$ determined that the closed basket-weave ankle tape technique is effective in limiting extreme ranges of motion in all directions. ${ }^{14}$ Additional research has found application restricts dorsiflexion, plantar flexion, and inversion when an ankle tape is applied. $^{18,25}$

Another topic that is discussed in research is how closed basket-weave ankle tape application might affect dynamic performance. Much of this literature looks at gait, agility, and functionality while the athlete is performing exercise, drills, and training. ${ }^{4-6,10,13,15,19,26-31,35-46}$ For example, Chin et $\mathrm{al}^{47}$ observed that ankle tape application can be used to assist gait training while preventing inversion of the foot and ankle. ${ }^{47}$ Other research has shown that ankle taping 
does not affect any planned reactive agility, vertical jump, or drills. ${ }^{13,19,40,41}$ In addition, Gribble et $\mathrm{al}^{42}$ has also demonstrated that a closed basket-weave ankle tape has no effect on muscle activity. $^{42}$

There may be some doubt regarding the usefulness of a closed basket-weave ankle tape across all sport activities. For sports such as football, basketball, and lacrosse, tape application with an athlete in a position of dorsiflexion may be ideal. However for athletes such as dancers, most of the movement requires plantar flexion at about 90-100 degrees along with 90-100 degrees of dorsiflexion of the first metatarsophalangeal joint. ${ }^{48}$ Although ankle tape application is a common practice and successful in preventing further ankle injury, it is not as common in the performing arts due to the limitations of range of motion. Ewalt ${ }^{49}$ has given some suggestions about taping for dancers. She recommended taping the ankle in dorsiflexion while using a stretchy tape for the heel locks. ${ }^{49}$ Anecdotal discussions with three athletic trainers who work with athletes in the performing arts revealed that they typically apply ankle tape in a neutral or plantar flexed position.

The purpose of this study is to identify whether applying an ankle tape in a neutral position, rather than a dorsiflexed position, provides similar range of motion restraints while not affecting performance. It is hypothesized that the neutral tape application will contribute to better dynamic performance while still providing support. 


\section{CHAPTER II}

\section{LITERATURE REVIEW}

The use of a closed basket-weave ankle tape has been a common practice for healthcare professionals to assist with those athletes who have sustained an ankle injury. For sports such as football, basketball, and lacrosse, ankle taping an athlete in a position of dorsiflexion may be ideal to prevent the mechanism of injury, hyper-plantarflexion and inversion. However for athletes within the performing arts, such as dancers, most of the movements require the ankle joint to be in this vulnerable position. In the performing arts setting, a closed-basket weave ankle tape is not as common because of its restriction on range of motion in which the dancer needs in order to perform their movement successfully. The purpose of this study is to identify whether application of an ankle tape in a neutral, relaxed position, rather than a dorsiflexed position, affect range of motion restraints and jump performance. To consider this question, we must understand the anatomy of the ankle, the etiology of ankle sprains, and how a healthcare professional might provide a closed basket-weave ankle tape in order to prevent re-injury. Knowledge of how a closed basket-weave ankle tape might restrict range of motion while not affecting dynamic performance is also pertinent for this study. Since this study focuses on dancers, it is important to understand the biomechanics of dance and how they might sustain an injury. Overall, the goal is to provide performing arts healthcare professionals another tool in order to provide a successful return to performance after sustaining an ankle injury.

\section{Ankle Anatomy}

Anatomy for the ankle joint is complex due to the many bones and articulations. We first begin with the bony structure. Starting from the knee down, we have the tibia and fibula bones that make up the top of the ankle mortise. ${ }^{50}$ The tibia is more medial, or closer to midline of the 
body, and the fibula is more lateral, further from the midline of the body. ${ }^{50}$ The tibia and fibula both have bony prominences that are at the distal ends called the malleolus. ${ }^{50}$ Both malleoli form the concave surface of the ankle joint. ${ }^{50}$ The convex surface that makes up the inferior portion of the ankle joint is the talus which rests inferiorly on the calcaneus. ${ }^{50}$ This joint is called the subtalar joint. 50

These bony articulations are then connected by tissue called ligaments. On the medial side, a triangular ligament called the deltoid ligament is what connects the superior and inferior ankle mortise on the medial side. ${ }^{50}$ The deltoid ligament is made up of three branches which first originate at the medial malleolus. The most anterior side of the ligament attaches to the navicular bone as well as the calcaneo-navicular ligament. ${ }^{50}$ This resists anterior translation of the ankle joint, inversion, and valgus tilt of the subtalar joint. ${ }^{51}$ The middle portion of this ligament attaches to the sustentaculum tali, which is a bony prominence of the calcaneus. ${ }^{50}$ This resists inversion of the ankle joint. ${ }^{51}$ The most posterior portion of the deltoid ligament attaches to a posterior prominence of the calcaneus called the astragalus. ${ }^{50}$ This posterior portion resists posterior translation of the ankle joint and internal rotation of the talus. ${ }^{51}$ On the lateral side of the ankle mortise, there are three ligaments that make up the lateral border of the ankle mortise. ${ }^{50}$ The most anterior portion of this ligament complex is the anterior talo-fibular ligament (ATFL) which connects the lateral malleolus to the calcaneus. ${ }^{50}$ The ATFL resists anterior translation of the talus in the ankle complex, external rotation of the fibular, and internal rotation of the talus. ${ }^{51}$ The calcaneo-fibular ligament (CFL) is posterior to the ATFL and connects the lateral malleolus to the calcaneus. ${ }^{50}$ This ligament mostly resists inversion of the ankle joint. ${ }^{51}$ The posterior talofibular ligament (PTFL) is the most posterior ligament of the lateral ligament complex which 
connects the lateral malleolus to the calcaneus on the astragalus. ${ }^{50}$ This ligament resists inversion, external rotation of the talus and internal rotation of the fibula. ${ }^{51}$

Although commonly known as a hinge-joint, ankle motion can be split into three planes of motion, sagittal plane, frontal plane, and transverse plane. ${ }^{51}$ In the sagittal plane, dorsiflexion and plantarflexion are the common movements. ${ }^{51-57}$ In the frontal plane, abduction and adduction of the talus occurs. ${ }^{51}$ Lastly, internal and external rotation of the talus in the ankle mortise takes place in the transverse plane. ${ }^{51}$ These motions are performed by the muscles that surround the ankle joint. Muscles that contribute to dorsi-flexion are the extensor digitorum longus, extensor hallicus longus, peroneus tertius, and the tibialis anterior. ${ }^{58}$ Muscles that contribute to plantar-flexion are the flexor digitorum longus, the flexor hallucis longus, the gastrocnemius, the peroneus brevis, the peroneus longus, the plantaris, the soleus, and the tibialis posterior. ${ }^{58}$ Muscles that assist the inversion motion are the extensor hallucis longus, the flexor digitorum longus, the flexor hallucis longus, the tibialis anterior, and the tibialis posterior. ${ }^{58}$ Muscles that assist with eversion are the extensor digitorum longus, the peroneus brevis, the peroneus longus, and the peroneus tertius. These muscles of the lower leg are divided into four compartments that are surrounded by tissue called fascia. ${ }^{58}$ The four compartments are the anterior compartment, the lateral compartment, the superficial compartment, and the deep posterior compartment. ${ }^{58}$ There are two common nerves from the sacral plexus that innervate these muscles. ${ }^{58}$ These two nerves are the common peroneal nerve and the tibial nerve. ${ }^{58}$ The common peroneal nerve branches to the deep peroneal nerve innervating the anterior compartment and the superficial peroneal nerve innervates the lateral compartment. ${ }^{58}$ The tibial nerve innervates the muscles in the medial compartment and the posterior compartment. ${ }^{58}$ 


\section{Ankle Injury}

Though there is much research in prevention, ankle sprains continue to be present and clinicians still have challenges with evaluation and treatment of these injuries. ${ }^{59}$ Usually with ankle sprains, both the ankle and subtalar joints are included. ${ }^{60}$ In order to understand ankle sprains, knowledge of anatomy is important. In the ankle mortise, the talus moves anterior and posterior between both malleoli during dorsiflexion and plantarflexion. ${ }^{61}$ The talus is shaped unevenly as it is smaller posteriorly and larger anteriorly. ${ }^{61}$ Because of this shape, the ankle is more stable in dorsiflexion than in plantarflexion. ${ }^{61}$ While in dorsiflexion, the anterior portion of the talus is positioned more in the ankle mortise creating stability. ${ }^{61}$ In contrast, when the talus moves into plantarflexion, the posterior talus is more in the ankle mortise. ${ }^{61}$ Because of its smaller shape, there is limited bony contact between the malleoli. ${ }^{61}$ This limited bony contact creates an unstable position for the ankle. ${ }^{61}$ The usual mechanism for ankle injury is rear foot supination. ${ }^{60}$ This includes ankle plantarflexion, subtalar inversion, and internal rotation. ${ }^{60}$ The “inversion" mechanism causes $85 \%$ of ankle sprains. ${ }^{60}$

The most common ligament that is injured in this unstable position is the ATFL. According to Peterson and Renstrom ${ }^{62}$, about $70 \%$ of ankle injuries result with isolated ATFL damage. The ATFL is the first ligament of the lateral ligament complex to become damaged because of the orientation and initial loading weakness. ${ }^{63}$ As the ankle moves into plantarflexion, the ATFL becomes a collateral ligament and moves in line with the fibula. ${ }^{61}$ This position makes the ATFL more prone to injury. ${ }^{61}$ The CFL and PTL follow after the ATFL, however damage to these two ligaments is not as common. ${ }^{62}$

Determining factors of ankle injury include joint position, magnitude of force, direction, rate of applied force, and resistance provided by joint structures. ${ }^{60}$ Predisposing factors for ankle 
sprains are still unpredictable. Current literature shows some agreement that gender of an athlete and general joint laxity is not a risk factor of lateral ankle sprains. ${ }^{64}$ There is little agreement within the literature about an athlete's height and weight, limb dominance, ankle joint laxity, anatomical alignment, and postural sway to be risk factors for an ankle injury. ${ }^{64}$ To assist with joint positioning to prevent injury, a closed basket-weave ankle tape may be applied.

\section{Ankle Taping}

The closed basket-weave ankle tape technique is commonly ankle tape that is used in physical activity in order to provide support to those athletes who sustain an ankle sprain. Athletic Trainers apply ankle tape in order to partially restrict movement in the direction of tissue trauma, typically inversion and plantarflexion. ${ }^{7,26,65,66}$ Prior to tape application, the athletic trainer (AT) places the ankle in 90 degrees dorsiflexion to limit plantarflexion when the tape is applied ${ }^{67}$ The AT begins with applying pre-tape, also known as "pre-wrap" to the injured ankle ${ }^{68}$ Then two proximal anchor strips are applied around the tibia and fibula just inferior to the muscle belly of the gastrocnemius ${ }^{67,68}$ Following the anchor strips, three stirrups are then applied starting from the medial anchor around the ventral foot near the calcaneus and up on the lateral anchor on the lower leg. ${ }^{67,68} \mathrm{An}$ anchor is applied after each stirrup strip. ${ }^{67,68}$ This is then followed by closing strips going from the beginning anchors to the true ankle joint. Two "heel locks" are then applied on each side going around the calcaneus in order to restrict inversion. ${ }^{67,68}$ The last strip of tape is a "figure-eight" pattern which goes around the dorsal foot and the distal tibia and fibula. ${ }^{65}$ Much of the current research states ankle taping assists with restricting range of motion, restricting ligament laxity, assisting with balance, and assisting with dynamic movement. $4-11,13-34,36-46,49,65,69-82$ 
Investigations of range of motion restrictions with an ankle tape has been conducted as early as 1963 . Malina ${ }^{17}$ observed the effect of tape on skin, tape on a stockinette, and the Louisiana Wrap and compared the support pre- and post- exercise. He found that tape on skin provided the most support pre and post exercise. ${ }^{17}$ While the Louisiana wrap provided the least support pre- and post- exercise. ${ }^{17}$ In 1976 , Glick ${ }^{72}$ looked at the comparisons of cloth wrap and tape wrap and its effect on the talar tilt. It was found that tape supported the talus more during exercise compared to the cloth wrap. ${ }^{72}$

As research progressed, a common finding was that ankle tape restricts ankle range of motion. ${ }^{5,9,28,30-32,34}$ In particular, plantarflexion and inversion can be restricted with the ankle tape. ${ }^{5,9,28,30-32,34}$ This is noteworthy as the combined motions of plantarflexion and inversion represent the most common positions for ankle sprains. Morris and Musnicki ${ }^{34}$ found that dorsiflexion and plantarflexion were restricted pre-exercise, however the tape loosened during exercise. Likewise inversion and eversion were also restricted pre and post exercise. ${ }^{34}$ Callaghan ${ }^{5}$ in his systematic review suggested that the closed basket-weave ankle tape seemed to decrease the amount of non-weight bearing talar tilt. Wilkerson ${ }^{30}$ in his study found that either the closed basket-weave ankle tape technique or a subtalar tape had a significant reduction in ankle range of motion. Fumich ${ }^{9}$ compared more of the goniometric measurements pre- and post-exercise with the application of an ankle tape. He found that plantarflexion was resisted by 4.18 degrees, dorsiflexion by 3.31 , inversion by 5.81 degrees, and eversion by 6.39 degrees. ${ }^{9}$ In most recent research, Sasadai ${ }^{28}$ looked at the effect of ankle taping and performance with kicking a soccer ball. He found that the tape did restrict maximal plantarflexion needed for the instep of a soccer kick. ${ }^{28}$ The taping resulted in a restriction of 55.2 degrees when the ankle was taped in 0 degrees of plantar flexion, a 40.9 degree restriction wheen the ankle was taped in 15 degrees of 
plantarflexion, and a 26.5 degree restriction when the ankle was taped in 30 degrees of plantarflexion. ${ }^{28}$

The use of different taping materials and braces have also been researched for the effects of range of motion. ${ }^{21,25}$ Purcell et $\mathrm{al}^{25}$ explored the difference in range of motion between white cloth tape and self-adherent tape before and after exercise. It was found that both conditions resist plantarflexion before and after exercise, however the self-adherent tape resisted inversion more than the white cloth tape. ${ }^{25}$ Myburgh et $\mathrm{al}^{21}$ compared elastic ankle guards and ankle tape before, during, and after exercise in squash players. She found that tape had a statistically significant restriction in range of motion compared to the elastic guards. ${ }^{21}$ She also found that zinc oxide tape provided the greatest restriction most of the time. ${ }^{21}$ Braces have also been proven to help restrict range of motion. ${ }^{7,10,21-23,74,76,78}$ Paris found that the brace restricted range of motion in plantarflexion and generally provided more post-activity support compared to tape. ${ }^{23}$

Much of the research on ankle tape application also assesses the effects on dynamic movement and the ability for the athlete to perform sport specific tasks. ${ }^{6,13,15,26-31,36-42,45,70,82}$ Meana $^{19}$ investigated the kinematics of tape application before and after a training session. The investigators found that ankle tape restricts maximal static range of motion before a training session. ${ }^{19}$ It was found that ankle supination during the breaking phase of gait was restricted with the application of an ankle tape. ${ }^{19} \mathrm{Chinn}^{47}$ also looked at gait kinematics after taping in participants with chronic ankle instability (CAI). The investigator found that taped CAI participants tend to be in a more neutral position at the different increments of the gait cycle. ${ }^{47}$ It was also found that taped CAI participants were less inverted during 51-61\% of the gait cycle. ${ }^{47}$ The researcher suggested that this might reduce the risk of ankle sprains due to better positioning throughout the gait cycle. ${ }^{47}$ 
When it comes to performing sports specific tasks, a majority of the research indicates that ankle tape does not have much effect. ${ }^{13,26,27,42}$ Quackenbush ${ }^{26}$ researched the effects of two adhesive ankle-taping methods on strength, power and range of motion in female athletes. It was found that although active range of motion was restricted by both the taping procedures, it had no effect on vertical jump and maximal voluntary contraction forces. ${ }^{26}$ Gribble et al ${ }^{42}$ also looked at ankle taping and the activation of the peroneal musculature during a lateral shuffle. It was found that bracing does not affect the activation of the peroneal musculature for a short period of activity and long period of activity. ${ }^{42}$ Ricard ${ }^{27}$ examined the potential difference between taping over pre-wrap and no pre-wrap on restricting dynamic and weight-bearing inversion. It was found that there were no differences between taping over pre-wrap and taping over bare skin when preventing the inversion mechanism. ${ }^{27}$ The time to maximum inversion in the taped conditions was greater than the no tape conditions and it was found that tape restricted inversion about 10 degrees before exercise. ${ }^{27}$ It was also found during this study that tape has to withstand the magnitude and rate of torque application caused by the athlete's center of mass. ${ }^{27}$ Jeffriess $^{13}$ also assessed the effect of ankle tape with dynamic movement by assessing the effects of preventative ankle tape on the change-of-direction and reactive agility and peak ankle muscle activity of basketball players. The researchers found that ankle tape had a minimal effect of muscle activity and does not affect planned reactive agility. ${ }^{13}$

Although much of the research states that ankle taping does not decrease athletic performance, there are others that state the ankle taping does have an effect. ${ }^{6,20,23,29,31}$ Wilkerson ${ }^{31}$ wrote a systematic review comparing and contrasting the pros and cons on ankle taping and its biomechanical and neuromuscular effects. One of the research articles he analyzed was Burks et $\mathrm{al}^{6}$. This article analyzed athletic performance with prophylactic ankle devices. ${ }^{6}$ It 
was found that ankle taping had produced a decrease in performance compared to a no tape condition. ${ }^{6}$ There was a $4 \%$ decrease in the vertical jump, $1.6 \%$ decrease in the shuttle run, and a $3.5 \%$ decrease in the sprint $(\mathrm{p}<0.05) .{ }^{6}$ Similarly, Paris ${ }^{38}$ observed the effects of the Swede-O brace, New Cross brace, the McDavid brace, and adhesive ankle taping on speed, balance, agility, and vertical jump. It was concluded that although speed, balance, and agility was not significantly affected, vertical jump was significantly affected with the New Cross brace with a decreased performance of $5.4 \%{ }^{38}$ Tape also decreased vertical jump performance by $2.4 \% .^{38}$ Metcalfe et $\mathrm{al}^{20}$ also assessed movement performance between moleskin tape, linen tape, and a lace up brace. It was found that vertical jump was significantly shorter and the agility test was significantly slower compared to a control of no support. ${ }^{20}$ Although not in Wilkerson's systematic review, Verbrugge ${ }^{29}$ assessed semi-rigid air-stirrup bracing and adhesive ankle taping on motor performance. It was determined that even though agility was not affected, vertical height seemed to decrease by $2.5 \% .^{29}$

\section{Dance Biomechanics}

Ankle injuries are not only common in the traditional sport setting, but in the dance setting as well. ${ }^{1,83-85}$ Many of the injuries of dancers usually occur during jumps, lifts, and high impact movements. ${ }^{86}$ Shah ${ }^{83}$ contributed to understanding dance injuries by analyzing injuries within professional modern dancers. She found that $18 \%$ of the total injuries of have been related to the ankle. ${ }^{83}$ In a study of Broadway dancers, $50 \%$ of the injuries were related to the foot and ankle. ${ }^{87}$ Hamilton $^{85}$ stated that most of the ankle injuries occur to the lateral ligaments of the ankle. ${ }^{85}$ Of those with lateral ankle injuries, about $76 \%$ of dancers miss full performances and $74 \%$ miss partial performancs. ${ }^{87}$ 
A review of the biomechanics of dance helps to explain why there is a high occurrence of ankle sprains in the dance population. At the ankle joint, the posterior talus, which is smaller than the anterior portion of the talus moves into the ankle mortise.$^{61}$ The ATFL is the primary stabilizing ligament when dancers are en pointe, or in a full plantar flexed position. ${ }^{88}$ This is because when the ankle is plantar flexed, the ATFL, which rests in a horizontal position, becomes taut in a collateral ligament position. ${ }^{89}$ Since this ligament on the lateral side is not as strong as the deltoid ligament complex, it is the most common injured ligament in the lateral ankle region. ${ }^{85}$ The primary muscles that are active in this plantar flexed position are the gastrocnemius and the soleus muscle. ${ }^{90}$ The tibialis posterior, peroneus longus, peroneus brevis, flexor hallicus longus, and the flexor digitorum longus are also muscles that also contribute to stability and assist with the hyper plantar flexed position. ${ }^{90,91}$ Since there is less bony contact in plantar flexion than in dorsiflexion, the soft tissue contributes more to provide dynamic stability. ${ }^{89}$ When the stability of the soft-tissue fails, then the ankle becomes unstable resulting in potential injury. ${ }^{48,85,92,93}$ Because of the soft tissue over-exertion, it has been hypothesized that tendinitis can occur after sustaining an ankle injury in dance. ${ }^{94}$

Aesthetics could also be another reason of why a dancer might be prone to injury. An example of this would be a "turnout" in ballet. This is defined as a rotation in the hips which then causes an outward rotation of the knees and feet. ${ }^{95}$ This allows greater extension of the leg especially to the side and the rear which is important for ballet technique. ${ }^{95}$ Most dancers would like a turnout of about 180 degrees. ${ }^{86}$ Sometimes dancers want to compensate alignment in the spine, hip, knee, and feet in order to achieve that perfect turnout. ${ }^{86}$ These compensations have been shown to have a high contribution to overuse injury in dance. ${ }^{86}$ 
Within the current study, the performance of a sauté jump is observed. A sauté jump is a bipedal jump most common in dance movement. ${ }^{96}$ To perform a sauté, the dancer starts in either first position or second position (Figure 1a), plies, bends the knees to lower the body (Figure 1b), and pushes off with their feet having the big toe be the last in contact with the floor. ${ }^{97}$ While in the air, the dancer hyper-plantar flexes the ankle to create an aesthetic point position (Figure 1c).$^{98}$ The dancer then lands the jump ending in the same plie position by "rolling" thru the foot starting from the toe and ending at the heel..$^{98}$

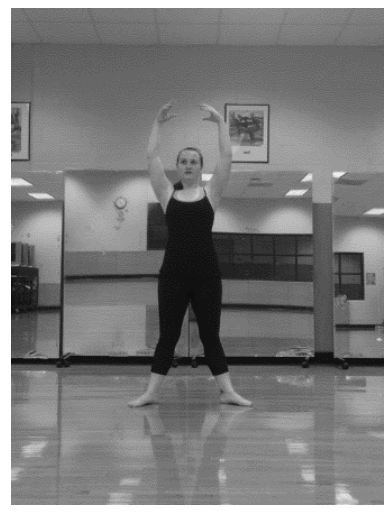

Figure 1a: Sauté Jump

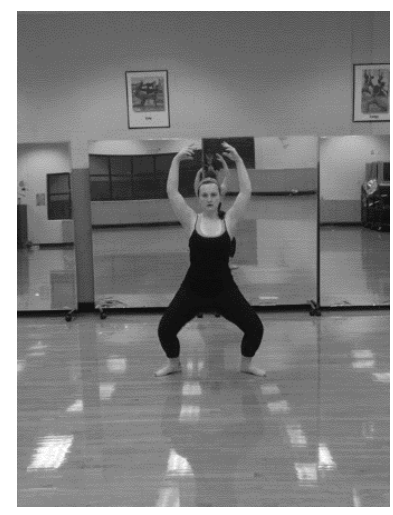

1b: Sauté Jump

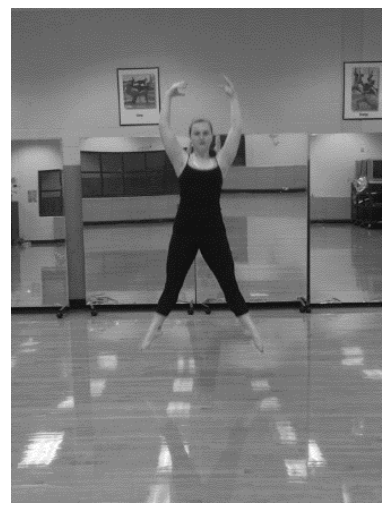

1c: Sauté Jump

To understand more of the biomechanics of a sauté jump, Fong Yan et al ${ }^{98}$ looked at performing sautés barefoot compared to shod from a biomechanical standpoint. We will first look at the motion of the hip. During the jump movement, the hip extends at toe strike in the air; and then moves into flexion during the landing of the jump. ${ }^{98}$ The hip then extends again in order to prepare for the next jump. ${ }^{98}$ At the knee joint, the knee is slightly extended at toe strike and then flexes at $49 \%$ of the stance phase. ${ }^{98}$ Then the knee extends at the toe off phase of the jump. ${ }^{98}$ At the ankle joint, the ankle plantar flexes at toe strike, reaches maximal dorsiflexion at the stance phase and then move into full plantarflexion at the toe off phase. ${ }^{98}$ 
Ground reaction force has also been evaluated for the sauté jump. ${ }^{99}$ Chockley ${ }^{99}$ conducted research comparing the sauté jump landed on the full foot and landing en pointe, or ankle hyper plantarflexion, for ballet dancers. A force plate was used to calculate these measurements. ${ }^{99}$ The study identified three phases of the jump. ${ }^{99}$ The first phase is the initial toe contact with the ground, the second is ball of the foot contacting the ground, and the third phase was identified as the heel contacting the ground. ${ }^{99}$ The mean maximum ground reaction force for the full foot was $735.93 \mathrm{~N} \pm 95.79 \mathrm{~N} .{ }^{99}$ The mean maximum ground reaction force for landing en pointe was $531.14 \mathrm{~N} \pm 82.28 . .^{99}$ The authors concluded that the lower mean from the en pointe position may be explained as the dancer loses vertical height due to the loss of range of motion for the optimal push from the ground. ${ }^{99}$ It was also found that the landing GRF absorbed by the lower extremities is twice the amount of time in jumps rolling through the foot compared to landing en pointe. ${ }^{99}$

\section{Conclusion}

This review of the literature provided insight on the anatomy of the ankle, the etiology of a lateral ankle sprain, a review of prophylactic taping and bracing to support the ankle, and a review of biomechanics of basic dance movement. Knowledge of these topics will help us understand the purpose of this study as to whether taping an ankle in a neutral position, rather than a dorsiflexed position, will provide similar range of motion restraints and not affect athletic performance. 


\section{CHAPTER III}

\section{METHODS}

\section{Study Design}

This was an assessor-blinded, crossover study to assess the difference in taping position and its effect on ankle range of motion, and ground reaction force at the ankle during a bipedal jump. The independent variable within the study included the three different taping conditions: taping in neutral, taping in dorsiflexion, and no tape. The dependent variables included ankle range of motion (ROM) and ground reaction force (GRF).

\section{Participants}

Based on a power analysis calculator with a significance level of 0.05 , an effect size of 0.5 , and a power of 0.8 , a sample of 16 participants was recommended for this study design. Participants were recruited from the Dance Performance Undergraduate Program in the College of Fine Arts at a large Midwest University. Participant's ages ranged from 18-30 years old (Mean Age 20 y/o \pm 1.68, Height $162.77 \mathrm{~cm} \pm 14.35$, Weight $60.21 \mathrm{~kg} \pm 8.32$. Inclusion criteria included dancers with no history of ankle injury in the past 6 months, no history of surgery on the ankle joint in the past 12 months. Participants also needed to have five or more years of experience in either ballet, modern, or jazz (Mean Experience Ballet 10.5 years \pm 5.66, Mean Experience Jazz 10.75 years \pm 4.92 , Mean Experience Modern $5.58 \pm 3.29$ ) and be enrolled in the collegiate dance program. All participants completed a written informed consent prior to participation per the university the Institutional Review Board guidelines. 


\section{Instrumentation}

A 12 inch biplane goniometer (Sammons Preston, Performance Health, Warrenville, IL) and a small standard 6 inch goniometer (Sammons Preston, Performance Health, Warrenville, IL) were used to measure ankle joint range of motion. Intra-rater reliability was established before data collection. Dorsiflexion ICC $=.82$, Plantarflexion $\mathrm{ICC}=.86$, Inversion $\mathrm{ICC}=.82$, Eversion ICC $=.95$. Two force plates were used to measure the ground reaction force at $1000 \mathrm{~Hz}$ (Advanced Mechanical Technology Incorporated, Newton, MA). ${ }^{100}$ Reflective markers, applied according to the Vicon Plug-In Gait templete (Vicon, Centennial, CO) were tracked with 10 Vicon infrared cameras at $200 \mathrm{~Hz}$ (Vicon, Oxford, United Kingdom). ${ }^{100}$

\section{Procedure}

All testing procedures were conducted in a university biomechanics laboratory. Data collection was completed in a single session. Participants were asked to dress in basic spandex athletic wear, allowing the lower leg to be exposed. Prior to data collections, participants completed a pre-participation questionnaire. After determining the participant met all the inclusion criteria, the participant completed an eight minute warm-up on a stationary bike. ROM and GRF were measured without any tape applied for baseline measurements on both ankles. Standardization of data collection included blinding the examiner regarding taped condition and having a trained research assistant perform all tape applications. After baseline measurements were recorded, a research assistant escorted the participant to a separate, closed off room where the participant received the first tape condition. Block randomization had been predetermined before overall data collection by the research assistant. For example, the first participant had both ankles taped in dorsiflexion (Figure 1b) for the first tape condition, while the next participant had both ankles taped in neutral, or "relaxed", "no muscle contraction," (Figure 1a) for the first tape 
condition. This back and forth pattern continued for all participants. After tape application was determined, the participant was instructed to go into either neutral or full dorsiflexion for the research assistant to apply a standard, closed basket ankle tape on both ankles. The evaluator, who was not present for either of the tape applications, measured range of motion and ground reaction force after the application of tape. After measurements were recorded the first tape condition, the tape was removed from the participant's ankle. The research assistant led the participant to the closed off room where the second tape condition was applied. The evaluator measured range of motion and ground reaction force for the second tape condition.

Measurements of ROM and GRF are explained later in this chapter. Once the second tape condition measurements were taken, the participant was able to remove both tape applications and data collection was complete.

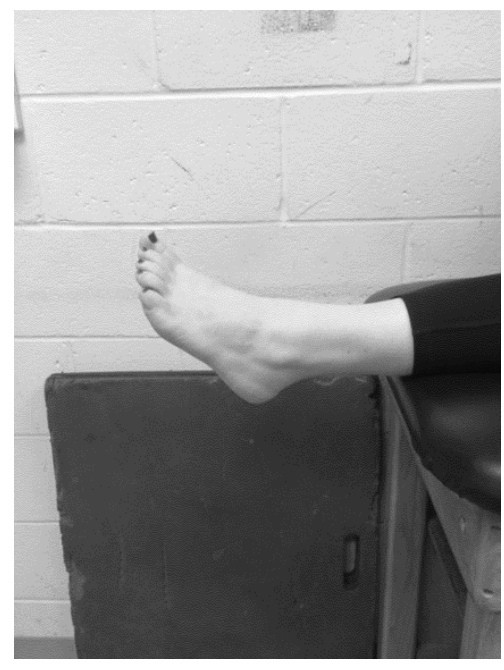

Figure 2a: Neutral Foot

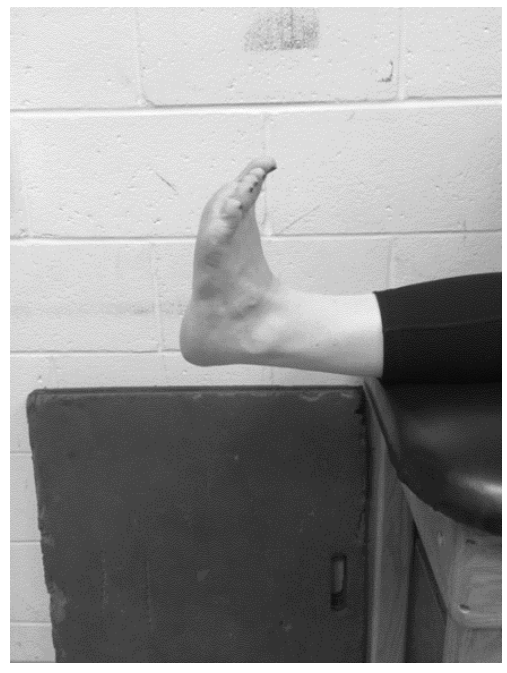

Figure 2b: Dorsiflexed Foot

\section{Ankle Tape Procedure}

A closed basket ankle tape was applied with the following procedure: 1) Patient positioned long-seated on a table 2) Patient is instructed to move ankle in either full dorsiflexion (Figure 1b) or neutral (Figure 1a) and hold for the application of tape 3) A small amount of 
adhesive spray was applied to the ankle 4) One pair of heel and lace pads with a small amount of lubricant was applied on the anterior side of the ankle and on the Achilles tendon 5) Pre-wrap was applied in a circular motion from the mid-foot to just below the muscle belly of the gastrocnemius 6) Two inch white-cloth tape (Thin-flex White Tape, Arrowhead Athletics, Andover, MA) was applied starting with one anchor around the mid-foot and at the base of the muscle belly of the gastrocnemius 7) Medial to lateral stirrups applied followed by another anchor at the base of the gastrocnemius. Repeat three times 8) Apply anchors down from the first top anchor to the ankle joint to "close off" ankle tape 9) Two heel locks were applied, one starting medial, one starting lateral 10) One figure-eight pattern was applied. Ankle tape was applied by same research assistant to control for taping variations.

\section{Ankle Range of Motion Measurement}

Ankle plantarflexion, dorsiflexion, inversion, and eversion were measured using the standard goniometer. A 12 inch biplane goniometer was used to measure dorsiflexion and plantarflexion. Participants were in a seated position with the knee fully extended and the foot off a treatment table. The ankle was placed in an anatomical position and the foot was in 0 degrees of inversion and eversion. The axis of the goniometer was aligned with the lateral malleolus. The proximal arm was in alignment with the long axis of the fibula, and the distal arm, or platform, was lined up with the bottom of the foot. The dorsiflexion measurement was taken first, followed by ankle plantarflexion measurement for all participants. Three trials were taken of each. Ankle inversion and eversion were measured next. Participants were in a long seated position on a table. With the 6 inch goniometer, the axis was placed on the anterior aspect of the ankle. The proximal arm was placed on the crest of the tibia, and the distal arm was placed 
along the second metatarsal. Inversion was measured first, followed by eversion. Three trials of each were taken of each direction.

\section{Ground Reaction Force Measurement}

Participants performed five trials of one sauté jump (bipedal vertical dance jump) at maximum power. ${ }^{103}$ Before baseline data collection, the option of two practice trials were given in order for the participant to feel comfortable with the technique. ${ }^{96}$ Markers for the optical motion capturing system were placed on the anterior iliac crest, iliac crest, lateral thigh, lateral knee, lateral shank, lateral malleolus, Achilles, and at the head of the $2^{\text {nd }}$ Metatarsal bilaterally in order to identify a kinetic marker. Arms were held in ballet $5^{\text {th }}$ position and the task was done with each foot on a single force plate while barefoot ${ }^{96}$ A 110 degree angle and a 130 degree angle was taped on the force plates in order to minimize variation of the participant's 'ballet turn-out". Trials were acceptable if participant was able to perform the jump while maintaining the trunk in an erect posture, keeping arms overhead, markers maintained on the lower extremities, and staying on the force plates throughout the trial. ${ }^{96}$ The Vicon Data was processed to determine the position of each lower leg segment during the time of the jump as well as the ground reaction force calculated by the force plates during the time of the jump. Peak ground reaction force was taken following max knee flexion of each participant (Figure 3). The average peak ground reaction force for the five trials was used for analysis. 

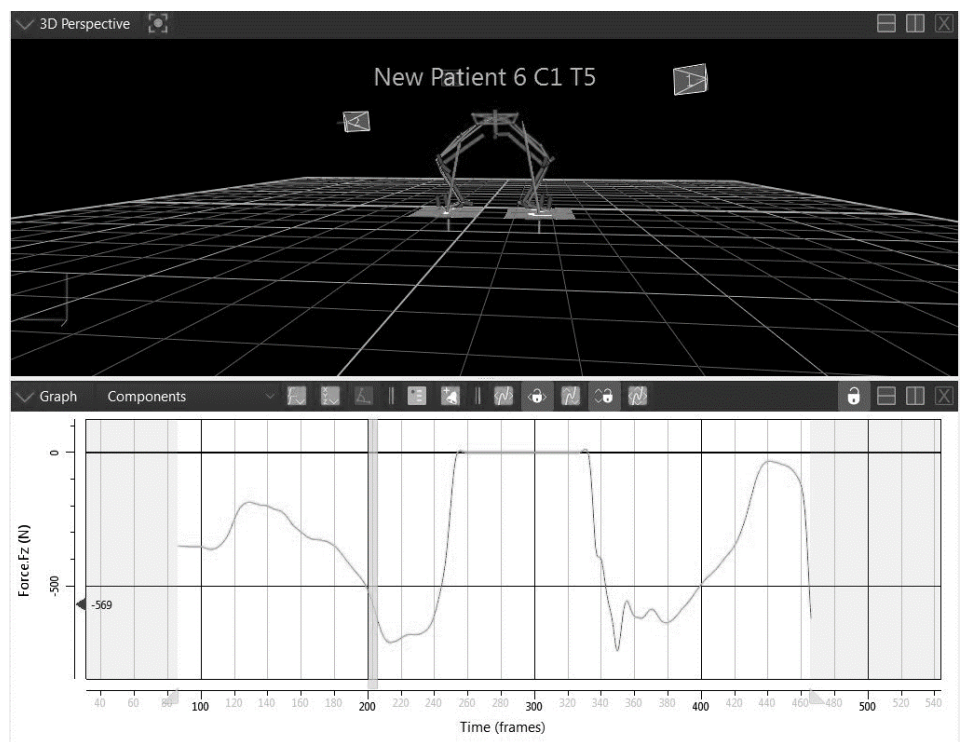

Figure 3: Vicon System Data

\section{Data Reduction and Statistical Analysis}

Raw data included range of motion measurements of dorsiflexion, plantarflexion, inversion, and eversion, and peak ground reaction forces. The average for all trials was used for analysis. A one-way repeated measures ANOVA was performed to compare the differences between the tape conditions with range of motion measurements and ground reaction force. This was done using SPSS (IBM SPSS Statistics for Windows, version 21.0, IBM Corp, Armonk, New York). Effect sizes were calculated by using Cohen's d and categorized as trivial $(\leq 0.20)$, small (0.21-0.49), moderate (0.50-0.79), and large ( $\geq 0.80)$. The alpha level with Bonferroni Correction was set at $\mathrm{p}<0.01$. 


\section{CHAPTER IV}

\section{RESULTS}

A one-way repeated measures ANOVA was conducted to compare range of motion and ground reaction force between the three conditions. The means and standard deviations are presented in Table 1. For dorsiflexion range of motion, there was a significant main effect for condition, Wilks' Lambda $=.53, \mathrm{~F}(2,22)=9.91, \mathrm{p}=.001$. Pair-wise comparisons revealed a significant difference between the no-tape and both the neutral $(\mathrm{p}=.01$, effect size $=.85,95 \% \mathrm{CI}$ $=.26$ to 1.44$)$ and dorsiflexed $(\mathrm{p}=.01$, effect size $=0.96,95 \% \mathrm{CI}=.36$ to 1.56$)$ taped condition.

For plantarflexion range of motion, there was a significant main effect for condition, Wilks' Lambda $=.26, \mathrm{~F}(2,22)=31.11, \mathrm{p}=.001$. Pair-wise comparisons revealed a significant difference between the no-tape and both the neutral $(\mathrm{p}=.001$, effect size $=1.81,95 \% \mathrm{CI} .57$ to $1.79)$ and dorsiflexed $(\mathrm{p}=.001$, effect size $=1.31,95 \% \mathrm{CI}=.69$ to 1.94$)$ taped condition.

For inversion range of motion, Mauchly's test indicated that the assumption of sphericity was violated, therefore the degrees of freedom were corrected using the Greenhouse-Geiser estimates of sphericity. Results showed a significant main effect for time for composite balance scores, $\mathrm{F}(1.47,22)=30.39, \mathrm{p}=0.001$. Follow-up analysis revealed inversion ranges of motion were significantly lower $(\mathrm{p}=0.001)$.

For eversion range of motion, there was a significant main effect for condition, Wilks' Lambda $=.63, \mathrm{~F}(2,22)=6.46, \mathrm{p}=.006$. Pair-wise comparisons revealed a significant difference between the no-tape and both the neutral $(\mathrm{p}=.004$, effect size $=.89,95 \% \mathrm{CI} .29$ to 1.48$)$ and dorsiflexed $(\mathrm{p}=.03$, effect size $=.69,95 \% \mathrm{CI}=.11$ to 1.27$)$ taped condition. 
Although there were significant difference between the no tape and the taped conditions, there was no significant differences between the dorsiflexed tape condition and the neutral taped conditions.

For ground reaction force, there was not a significant main effect for condition, Wilks' Lambda $=.85, \mathrm{~F}(2,22)=1.81, \mathrm{p}=.186$

Table 1. Means and Standard Deviations

\begin{tabular}{llll}
\hline Variable & No-Tape & Neutral Condition & Dorsiflexed Condition \\
\hline DF ROM & $8.58^{\circ} \pm 4.84$ & $1.79^{\circ} \pm 10.26^{*}$ & $2.57^{\circ} \pm 7.38^{*}$ \\
\hline PF ROM & $44.24^{\circ} \pm 4.97$ & $38.65^{\circ} \pm 4.46^{*}$ & $37.61^{\circ} \pm 5.07^{*}$ \\
\hline INV & $27.58^{\circ} \pm 7.42$ & $20.82^{\circ} \pm 4.58^{*}$ & $21.18^{\circ} \pm 5.01^{*}$ \\
ROM & & & $13.85^{\circ} \pm 3.10^{*}$ \\
\hline EVR & $16.37^{\circ} \pm 4.15$ & $13.24^{\circ} \pm 2.80^{*}$ & \\
ROM & & & $651.40 \mathrm{~N} \pm 136.15$
\end{tabular}

*Significant Difference between the No-tape Condition $(\mathrm{p}<.05)$ 


\section{CHAPTER V}

\section{DISCUSSION}

The application of a closed basket-weave ankle tape is commonly used to partially restrict the movement of the ankle joint in a plantar flexed, inverted position that was the likely mechanism for the initial injury. ${ }^{2,3}$ Literature has acknowledged that ankle tape application can limit range of motion of the ankle, and maintain performance. ${ }^{4-32}$ It is unclear how taping in this position affects range of motion or dynamic performance when assessing the extreme demands of the ankle during dance movement. Therefore, the purpose of this study was to identify whether tape application in a neutral position, rather than a dorsiflexed position, provides similar range of motion restraints while not affecting jump performance.

Results of this study found that there is no significant difference between ground reaction forces between the tape conditions and no tape $(\mathrm{p}=.186)$. These results are similar to the research conducted by Quackenbush ${ }^{26}$ who questioned the effects of two adhesive ankle-taping methods on strength, power and range of motion in female athletes. The author found that although active range of motion was restricted by both the taping procedures, it had no effect on vertical jump and maximal voluntary contraction forces. ${ }^{26}$ Jeffriess $^{13}$ also assessed the effect of ankle tape with dynamic movement by assessing the effects of preventative ankle tape on the change-of-direction and reactive agility and peak ankle muscle activity of basketball players. Our results compare similarly to the results with this study which found that ankle tape had a minimal effect on muscle activity and does not affect planned reactive agility. ${ }^{13}$ Distefano $^{41}$ also found very similar results when looking at prophylactic ankle bracing and its effects on ankle and knee range of motion and on vertical ground reaction force. ${ }^{41}$ It was found that vertical ground reaction force was not affected with the use of the prophylactic brace. ${ }^{41}$ 
Although no significance was found in jump performance, this study did find there was a significant difference between ranges of motion of the no-tape condition when compared to both taped conditions. Our findings compare similarly to the previous research that concluded that an ankle tape restricts ankle range of motion..$^{5,9,28,30-32,34}$ Our findings also are in agreement with prior research that plantarflexion and inversion are restricted with ankle tape. ${ }^{5,9,28,30-32,34}$ This is noteworthy as the combined motions of plantarflexion and inversion represent the most common positions for ankle sprains. Morris and Musnicki ${ }^{34}$ found that dorsiflexion and plantarflexion was restricted pre-exercise. Likewise inversion and eversion was also restricted pre- and postexercise. ${ }^{34}$ In our study, eversion was also found to be statistically significant for both tape conditions when being compared to the no-tape condition. Our results also relate to those of Wilkerson ${ }^{30}$ and his study. He found that both the closed basket-weave ankle tape technique and a subtalar tape had a significant reduction in ankle range of motion. ${ }^{32}$ Findings for our research were also similar to a recent study that was performed by Sasadai. ${ }^{28}$ While looking at the effect of ankle taping and performance with kicking a soccer ball, he found that the tape did restrict maximal plantarflexion needed for the instep of a soccer kick. ${ }^{28}$

Although it was found that there was a significant difference in range of motion between the no-tape condition and both taping conditions, it was found that there was no significant difference between ranges of motion of the dorsiflexed tape condition and the neutral tape condition. From a review of current literature, there have been no other studies that have looked at alternate foot positioning with the application of closed basket-weave ankle tape.

From the results of this study, it can be concluded that foot positioning, with either the ankle dorsiflexed or in a neutral position, does not affect ground reaction forces or range of motion measures. The significance of this finding is that athletic trainers who work with dancers 
can provide a closed basket-weave ankle tape and either tape in a dorsiflexed position or neutral position knowing that there is a similar restriction of inversion range of motion while not affecting jump performance.

Although the results indicate that foot positioning is not significant with the variables assessed, it is important to keep in mind how the patient might feel about the application of the ankle tape. As evidence-based practice clinicians, one not only uses research and experience to make clinical decisions, but also considers what the patient feels. ${ }^{104}$ If a dancer feels that a closed basket-weave ankle tape taped in a dorsiflexed position is restricting in ROM and is therefore unable to perform that movement, then the athletic trainer should consider the preference of the athlete and try to adapt the tape so that the patient feels confident in the ankle tape application.

\section{Limitations}

For this study, as with all studies, there are limitations to the methods. One limitation that might conflict with this research study include factors outside of athletic training might not allow the athletic trainers to tape a closed basket-weave ankle tape to prevent from further ankle injury. Restrictions of costuming might limit the use of a closed basket-weave ankle tape because of its "bulky" appearance. Overall aesthetic appearance of a performance was another limitation that may clash with the findings of our data. To adapt to the aesthetic appearances, an athletic trainer might tape in a different way in order to prevent the reoccurring mechanism of injury while maintain aesthetic appearance.

\section{Future research}

Our results are the first to examine foot positioning with a closed basket-weave ankle tape application. There are other variables that need to be understood in order to completely understand different foot positioning in applying a closed basket-weave ankle tape. Variables 
such as ligament laxity and passive range of motion are some examples of variables that should be studied in future research. Functional range of motion should also be assessed with this type of ankle taping. In a study conducted by Dickson ${ }^{105}$, she found that using an inclinometer is best to assess functional dorsiflexion and plantarflexion in modern dancers. ${ }^{105}$ Other performance variables in dancers should also be considered for future research. This might include pirouette turns, single leg balances, and leaps. Assessing joint angles and the difference between tape conditions while performing a specific activity should be considered for future research as well. Comparing different methods of preventative ankle taping compared to a closed basket-weave ankle tape during additional dance movements would provide additional evidence for the best methods of ankle injury prevention in the performing arts. Retrieving anecdotal evidence from dancers about the use of different tape conditions should also be assessed for future research.

\section{Conclusions}

Results of this study show that foot positioning during a closed basket-weave ankle tape application does not affect jump performance. Results also show that applying a close basketweave ankle tape method does restrict range of motion, however the foot positioning does not significantly affect overall range of motion restriction. With this information, the athletic trainer can provide an alternative to a traditional closed-basket weave tape application that may be more comfortable for dancers while still protecting the soft tissue of the ankle. 


\section{REFERENCES}

1. Fong DT, Hong Y, Chan LK, Yung PS, Chan KM. A systematic review on ankle injury and ankle sprain in sports. Sports Med. 2007;37(1):73-94.

2. Prentice W. Principles of athletic training. 14th ed. New York: McGraw-Hill; 2011:224.

3. Pope MH, Renstrom P, Donnermeyer D, Morgenstern S. A comparison of ankle taping methods. Med Sci Sports Exerc. 1987;19(2):143-147.

4. Alt W, Lohrer H, Gollhofer A. Functional properties of adhesive ankle taping: Neuromuscular and mechanical effects before and after exercise. Foot Ankle Int. 1999;20(4):238-245.

5. Callaghan MJ. Role of ankle taping and bracing in the athlete. Br J Sports Med. 1997;31(2):102-108.

6. Burks RT, Bean BG, Marcus R, Barker HB. Analysis of athletic performance with prophylactic ankle devices. Am J Sports Med. 1991;19(2):104-106 3p.

7. Eils E, Imberge S, Voelker K, Rosenbaum D. Passive stability characteristics of ankle braces and tape in simulated barefoot and shod conditions. Am J Sports Med. 2007;35(2):282-287.

8. Firer P. Effectiveness of taping for the prevention of ankle ligament sprains. Br J Sports Med. 1990;24(1):47-50.

9. Fumich RM, Ellison AE, Guerin GJ, Grace PD. The measured effect of taping on combined foot and ankle motion before and after exercise. Am J Sports Med. 1981;9(3):165. 
10. Gehlsen GM, Pearson D, Bahamonde R. Ankle joint strength, total work, and ROM: Comparison between prophylactic devices. J Athl Train. 1991;26(1):62-65.

11. Hubbard TJ, Cordova M. Effect of ankle taping on mechanical laxity in chronic ankle instability. Foot Ankle Int. 2010;31(6):499-504.

12. Hunt E, Short S. Collegiate athletes' perceptions of adhesive ankle taping: A qualitative analysis. J Sport Rehab. 2006;15(4):280-298.

13. Jeffriess MD, Schultz AB, McGann TS, Callaghan SJ, Lockie RG. Effects of preventative ankle taping on planned change-of-direction and reactive agility performance and ankle muscle activity in basketballers. Journal of Sports Science \& Medicine. 2015;14(4):864-876.

14. Karlsson J, Sward L, Andreasson GO. The effect of taping on ankle stability: Practical implications. Sports Medicine. 1993;16(3):210-215.

15. Koyama K, Kato T, Yamauchi J. The effect of ankle taping on the ground reaction force in vertical jump performance. Journal of Strength \& Conditioning Research (Lippincott Williams \& Wilkins). 2014;28(5):1411-1417.

16. Larsen E. Taping the ankle for chronic instability. Acta Orthop Scand. 1984;55(5):551.

17. Malina RM. Effect of exercise upon the measurable supporting strength of cloth and tape ankle wraps. Research Quarterly of the American Association for Health, Physical Education \& Recreation. 1963;34:158-165. 
18. Manfroy PP, Ashton-Miller J, Wojtys EM. The effect of exercise, prewrap, and athletic tape on the maximal active and passive ankle resistance to ankle inversion. Am J Sports Med. 1997;25(2):156-163.

19. Meana M, Alegre LM, Elvira JL, Aguado X. Kinematics of ankle taping after a training session. Int J Sports Med. 2008;29(1):70-76.

20. Metcalfe RC, Schlabach GA, Looney MA, Renehan EJ. A comparison of moleskin tape, linen tape, and lace-up brace on joint restriction and movement performance. $J$ Athletic Train. 1997;32(2):136-140 5p.

21. Myburgh KH, Vaughan CL, Isaacs SK. The effects of ankle guards and taping on joint motion before, during, and after a squash match. Am J Sports Med. 1984;12(6):441.

22. Papadopoulos ES, Nicolopoulos C, Anderson EG, Curran M, Athanasopoulos S. Review: The role of ankle bracing in injury prevention, athletic performance and neuromuscular control: A review of the literature. The Foot. 2005;15:1-6.

23. Paris DL, Vardaxis V, Kokkaliaris J. Ankle ranges of motion during extended activity periods while taped and braced. J Athletic Train. 1995;30(3):223-228 6p.

24. Pederson TS, Ricard MD. The effects of spatting and ankle taping on inversion before and after exercise. Journal of Athletic Training (National Athletic Trainers' Association). 1997;32(1):29.

25. Purcell SB, Schuckman BE, Docherty CL, Schrader J, Poppy W. Differences in ankle range of motion before and after exercise in 2 tape conditions. Am J Sports Med. 2009;37(2):383-389. 
26. Quackenbush KE, Barker PR, Stone Fury SM, Behm DG. The effects of two adhesive ankletaping methods on strength, power, and range of motion in female athletes. N Am J Sports Phys Ther. 2008;3(1):25-32.

27. Ricard MD, Sherwood SM. Effects of tape and exercise on dynamic ankle inversion. Journal of Athletic Training (National Athletic Trainers' Association). 2000;35(1):31.

28. Sasadai J, Urabe Y, Maeda N, Shinohara H, Fujii E. The effect of ankle taping to restrict plantar flexion on ball and foot velocity during an instep kick in soccer. J Sport Rehab. 2015;24(3):261-267.

29. Verbrugge JD. The effects of semirigid air-stirrup bracing vs. adhesive ankle taping on motor performance. J Orthop Sports Phys Ther. 1996;23(5):320-325 6p.

30. Wilkerson GB. Comparative biomechanical effects of the standard method of ankle taping and a taping method designed to enhance subtalar stability. Am J Sports Med. 1991;19(6):588595.

31. Wilkerson GB. Biomechanical and neuromuscular effects of ankle taping and bracing. $J$ Athl Train. 2002;37(4):436-445.

32. Wilkerson GB, Doty JF, Gurchiek LR, Hollis JM. Analysis of rotary ankle instability and taping restraint in a cadaver specimen. (cover story). Athletic Therapy Today. 2010;15(4):9.

33. Martin N, Harter RA. Comparison of inversion restraint provided by ankle prophylactic devices before and after exercise. J Athletic Train. 1993;28(4):324-361 8p. 
34. Morris HH, Musnicki W, 3. The effect of taping on ankle mobility following moderate exercise. J Sports Med Phys Fitness. 1983;23(4):422-426.

35. Hansen KT, Cronin JB, Newton MJ. The reliability of linear position transducer and force plate measurement of explosive force-time variables during a loaded jump squat in elite athletes. Journal of Strength and Conditioning Research. 2011;25(5):1447-1456.

36. Halim-Kertanegara S, Raymond J, Hiller CE, Kilbreath SL, Refshauge KM. The effect of ankle taping on functional performance in participants with functional ankle instability. Physical Therapy in Sport. 2016.

37. Hopper DM, Grisbrook TL, Finucane M, Nosaka K. Original research: Effect of ankle taping on angle and force matching and strength of the plantar flexors. Physical Therapy in Sport. 2014;15:254-260.

38. Paris DL. The effects of the swede-O, new cross, and McDavid ankle braces and adhesive ankle taping on speed, balance, agility, and vertical jump. J Athl Train. 1992;27(3):253-256.

39. Sanioglu A, Ergun S, Erkmen N, Taskin H, Goktepe AS, Kaplan T. The effect of ankle taping on isokinetic strength and vertical jumping performance in elite taekwondo athletes. Isokinetics Exerc Sci. 2009;17(2):73-78 6p.

40. Bot SDM, Verhagen EALM, Van Mechelen W. The effect of ankle bracing and taping on functional performance: A review of the literature. International SportMed Journal. 2003;4(5):114. 
41. Distefano LJ, Padua DA, Brown CN, Guskiewicz KM. Lower extremity kinematics and ground reaction forces after prophylactic lace-up ankle bracing. Journal of Athletic Training (National Athletic Trainers' Association). 2008;43(3):234-241.

42. Gribble PA, Radel S, Armstrong CW. Original research: The effects of ankle bracing on the activation of the peroneal muscles during a lateral shuffling movement. Physical Therapy in Sport. 2006;7:14-21.

43. Hopper DM, Grisbrook TL, Finucane M, Nosaka K. Effect of ankle taping on angle and force matching and strength of the plantar flexors? Physical Therapy in Sport. 2014;15(4):254260.

44. Kuni B, Mussler J, Kalkum E, Schmitt H, Wolf SI. Effect of kinesiotaping, non-elastic taping and bracing on segmental foot kinematics during drop landing in healthy subjects and subjects with chronic ankle instability. Physiotherapy. 2015.

45. Paulson S, Braun WA. Prophylactic ankle taping: Influence on treadmill-running kinematics and running economy. Journal of Strength \& Conditioning Research (Lippincott Williams \& Wilkins). 2014;28(2):423-429.

46. Raymond J, Nicholson LL, Hiller CE, Refshauge KM. The effect of ankle taping or bracing on proprioception in functional ankle instability: A systematic review and meta-analysis. Journal of Science \& Medicine in Sport. 2012;15(5):386-392. 
47. Chinn L, Dicharry J, Hart JM, Saliba S, Wilder R, Hertel J. Gait kinematics after taping in participants with chronic ankle instability. Journal of Athletic Training (Allen Press). 2014;49(3):322-330.

48. Kennedy JG, Hodgkins CW, Colombier J, Guyette S, Hamilton WG. Foot and ankle injuries in dancers. International SportMed Journal. 2007;8(3):141-165.

49. Ewalt KL. Bandaging and taping considerations for the dancer. J Dance Med Sci. 2010;14(3):103-113.

50. Gray H. Articulations. In: Pick T, Howden R, eds. Gray's anatomy. ; 2010:254-255-257.

51. Rasmussen O. Stability of the ankle joint. analysis of the function and traumatology of the ankle ligaments. Acta Orthop Scand Suppl. 1985;211:1-75.

52. Bonnin JG. Injuries to the ankle. . 1950.

53. Boone DC, Azen SP. Normal range of motion of joints in male subjects. J Bone Joint Surg Am. 1979;61(5):756-759.

54. Glanville AD, Kreezer G. The maximum amplitude and velocity of joint movements in normal male human adults. Human Biology. 1937(2):197.

55. Lindsjö U. Operative treatment of ankle fractures. Acta Orthop Scand Suppl. 1981;189:1131.

56. Sammarco GJ, Burstein AH, Frankel VH. Biomechanics of the ankle: A kinematic study. Orthop Clin North Am. 1973;4(1):75-96. 
57. Weseley MS, Koval R, Kleiger B. Roentgen measurement of ankle flexion--extension motion. Clin Orthop Relat Res. 1969;65:167-174.

58. Starkey C, Brown S, Ryan J. Ankle and leg pathologies. In: McDonald Q, ed. Examination of orthopedic and athletic injuries. ; 2010:225-226-230.

59. Safran MR, Benedetti RS, Bartolozzi AR,3rd, Mandelbaum BR. Lateral ankle sprains: A comprehensive review: Part 1: Etiology, pathoanatomy, histopathogenesis, and diagnosis. Med Sci Sports Exerc. 1999;31(7 Suppl):S429-37.

60. Whiting WC, Zernicke RF. Ankle sprain. In: Robertson L, ed. Biomechanics of musculoskeletal injury. 2nd ed. Human Kinetics; 2008:192.

61. Carr JB. Malleolar fractures and soft tissue injuries of the ankle. In: Browner BD, Jupiter JB, Levine AM, Trafton PT, eds. Skeletal trauma: Basic science, management, and reconstruction. 3rd ed. Philadelphia: Saunders; 2003.

62. Peterson L. Sports injuries : Their prevention and treatment. Human Kinetics; 2001.

63. Siegler S, Block J, Schneck CD. The mechanical characteristics of the collateral ligaments of the human ankle joint. Foot Ankle. 1988;8(5):234-242.

64. Beynnon BD, Murphy DF, Alosa DM. Predictive factors for lateral ankle sprains: A literature review. Journal of Athletic Training (National Athletic Trainers' Association). 2002;37(4):376. 
65. Miralles I, Monterde S, Montull S, Salvat I, Fernández-Ballart J, Beceiro J. Ankle taping can improve proprioception in healthy volunteers. Foot \& Ankle International. 2010;31(12):10991106.

66. Knight AC, Weimar WH. Effects of previous lateral ankle sprain and taping on the latency of the peroneus longus. Sports Biomechanics. 2012;11(1):48-56.

67. Perrin DH. Athletic taping and bracing. Champaign, IL : Human Kinetics, c2012; 3rd ed; 2012.

68. Arnheim DD, Prentice WE. Principles of athletic training. McGraw-Hill; 2000.

69. Ambegaonkar JP, Redmond CJ, Winter C, et al. Ankle stabilizers affect agility but not vertical jump or dynamic balance performance. Foot Ankle Spec. 2011;4(6):354-360.

70. Koyama K, Kato T, Yamauchi J. The effect of ankle taping on the ground reaction force in vertical jump performance. J Strength Cond Res. 2014;28(5):1411-1417.

71. Barkoukis V, Sykaras E, Costa F, Tsorbatzoudis H. Effectiveness of taping and bracing in balance. Perceptual \& Motor Skills. 2002;94(2):566.

72. Glick JM, Gordon RB, Nishimoto D. The prevention and treatment of ankle injuries. Am J Sports Med. 1976;4(4):136.

73. Heit EJ, Lephart SM. The effect of ankle bracing and taping on joint position sense in the stable ankle. J Sport Rehab. 1996;5(3):206. 
74. Kemler E, van dP, Schmikli S, Huisstede B, Hoes A, Backx F. Effects of soft bracing or taping on a lateral ankle sprain: A non-randomised controlled trial evaluating recurrence rates and residual symptoms at one year. Journal of Foot \& Ankle Research. 2015;8(1):1-8.

75. Leanderson J, Ekstam S, Salomonsson C. Taping of the ankle - the effect on postural sway during perturbation, before and after a training session. Knee Surgery, Sports Traumatology, Arthroscopy. 1996;4(1):53-56.

76. Ozer D, Senbursa G, Baltaci G, Hayran M. The effect on neuromuscular stability, performance, multi-joint coordination and proprioception of barefoot, taping or preventative bracing. The Foot. 2009;19:205-210.

77. Refshauge KM, Raymond J, Kilbreath SL, Pengel L, Heijnen I. The effect of ankle taping on detection of inversion-eversion movements in participants with recurrent ankle sprain. Am J Sports Med. 2009;37(2):371-375 5p.

78. Simon J, Donahue M. Effect of ankle taping or bracing on creating an increased sense of confidence, stability, and reassurance when performing a dynamic-balance task. J Sport Rehab. 2013;22(3):229-233.

79. Spanos S, Brunswic M, Billis E. The effect of taping on the proprioception of the ankle in a non-weight bearing position, amongst injured athletes. The Foot. 2008;18:25-33.

80. Stanek JM, Wisniewski A, Zander O. No difference in prophylactic support provided by either cloth or self-adherent tape. Athletic Training \& Sports Health Care: The Journal for the Practicing Clinician. 2016;8(1):8-16. 
81. Vaes P, De Boeck H, Handelberg F, Opdecam P. Comparative radiological study of the influence of ankle joint strapping and - - taping on ankle stability*. J Orthop Sports Phys Ther. $1985 ; 7(3): 110-114$.

82. Wheeler TJ, Basnett CR, Hanish MJ, et al. Fibular taping does not influence ankle dorsiflexion range of motion or balance measures in individuals with chronic ankle instability. Journal of Science \& Medicine in Sport. 2013;16(6):488-492.

83. Shah S, Weiss DS, Burchette RJ. Injuries in professional modern dancers incidence, risk factors, and management. Journal of Dance Medicine \& Science. 2012;16(1):17-25.

84. Russell JA. Acute ankle sprain in dancers. Journal of Dance Medicine \& Science. 2010;14(3):89-96.

85. Hamilton WG. Sprained ankles in ballet dancers. Foot Ankle. 1982;3(2):99-102.

86. van Merkensteijn GG, Quin E. Assessment of compensated turnout characteristics and their relationship to injuries in university level modern dancers. Journal of Dance Medicine \& Science. 2015;19(2):57-62.

87. Bronner S, Brownstein B. Profile of dance injuries in a broadway show: A discussion of issues in dance medicine epidemiology. Journal of Orthopaedic \& Sports Physical Therapy. 1997;26(2):87-94.

88. Bahr R, Pena F, Shine J, Lew WD, Engebretsen L. Ligament force and joint motion in the intact ankle: A cadaveric study. Knee Surg Sports Traumatol Arthrosc. 1998;6(2):115-121. 
89. Russell JA, McEwan IM, Koutedakis Y, Wyon MA. Clinical anatomy and biomechanics of the ankle in dance. Journal of Dance Medicine \& Science. 2008;12(3):75-82.

90. Floyd RT, Thompson CW. Manual of structural kinesiology. . 2004.

91. Magee DJ. Orthopedic physical assessment. . 2002.

92. Gerber JP, Williams GN, Scoville CR, Arciero RA, Taylor DC. Persistent disability associated with ankle sprains: A prospective examination of an athletic population. Foot Ankle Int. 1998;19(10):653-660.

93. Wiesler ER, Hunter DM, Martin DF, Curl WW, Hoen H. Ankle flexibility and injury patterns in dancers. Am J Sports Med. 1996;24(6):754-757.

94. Ritter S, Moore M. The relationship between lateral ankle sprain and ankle tendinitis in ballet dancers. Journal of Dance Medicine \& Science. 2008;12(1):23-31.

95. Grieg V. Inside ballet technique. Hightstown, NJ: Princeton Book Company. 1994.

96. Jarvis DN, Kulig K. Pointing the foot without sickling: An examination of ankle movement during jumping. Med Probl Perform Artists. 2015;30(1):61-65 5p.

97. Laws K. Glossary. In: Physics and the art of dance. Oxford University Press; 2002:230-231.

98. Fong Yan A, Hiller C, Sinclair PJ, Smith RM. Kinematic analysis of sautés in barefoot and shod conditions. Journal of Dance Medicine \& Science. 2014;18(4):149-158. 
99. Chockley C. Ground reaction force comparison between jumps landing on the full foot and jumps landing en pointe in ballet dancers. Journal of Dance Medicine \& Science. 2008;12(1):58.

100. McCaw ST, Gardner JK, Stafford LN, Torry MR. Filtering ground reaction force data affects the calculation and interpretation of joint kinetics and energetics during drop landings. Journal of Applied Biomechanics. 2013;29(6):804-809.

101. Dowling JJ, Vamos L. Identification of kinetic and temporal factors related to vertical jump performance. Journal of Applied Biomechanics. 1993;9(2):95-110.

102. Greiner AC, Knebel E. Health professions education : A bridge to quality. Washington, D.C. : National Academies Press, c2003; 2003.

103. Dickson D, Hollman-Gage K, Ojofeitimi S, Bronner S. Comparison of functional ankle motion measures in modern dancers. Journal of Dance Medicine \& Science. 2012;16(3):116125. 